\title{
Induction of the Myelin Proteolipid Protein (PLP) Gene in C6 Glioblastoma Cells: Functional Analysis of the PLP Promotor
}

\author{
Klaus-Armin Nave and Greg Lemke \\ Molecular Neurobiology Laboratory, The Salk Institute for Biological Studies, La Jolla, California 92037
}

The terminal differentiation of postmitotic oligodendrocytes is marked by the induction of myelin-specific genes. In this report, we demonstrate that culture conditions that induce oligodendrocyte differentiation of glial progenitor cells also induce differentiation of $\mathbf{C 6}$ glioblastoma cells, as monitored by activated transcription of the gene encoding proteolipid protein (PLP), the major myelin protein of the CNS. When assayed by transfections of hybrid reporter plasmids, the transcriptional control region of the PLP gene is preferentially active in differentiated $C 6$ cells and contains both positive and negative cis-regulatory elements. In general, functional identification of these elements is well correlated with the binding sites of glial nuclear proteins, as visualized by the presence of DNase I-protected footprints. A sequence within one positive cis-regulatory element of the PLP gene is conserved in the control regions of three other myelinspecific genes, suggesting that their coordinate transcription may involve a common regulatory mechanism.

The formation of myelin is dependent upon the developmentally regulated expression of a set of glial-specific genes. These genes encode the proteolipid protein (PLP), myelin basic protein (MBP), 2',3' cyclic nucleotide-phoshodiesterase (CNP), myelinassociated glycoprotein (MAG), protein zero $\left(\mathrm{P}_{0}\right)$, and other proteins unique to myelin. Important insights about the structure and function of these proteins have been gained from the cloning of their cDNAs, from their functional expression in heterologous cells, and from the molecular analysis of mutations in myelin-deficient mice (reviewed in Lemke, 1988). Very little is known about the mechanisms underiying the induction and regulated expression of these myelin-specific genes in developing oligodendrocytes, however.

Antibodies against stage-specific cell surface markers (Schachner et al., 1981) have been used to monitor the differentiation of oligodendroglial precursor cells in mixed primary cell cultures. In dissociated cultures of rat optic nerve, bipotential pre-

\footnotetext{
Received Nov. 29, 1990; revised Mar. 27, 1991; accepted May 3, 1991

We thank Danny Ortuño for excellent technical assistance, Drs. H. Mangalam, E. Monuki, and G. Weinmaster for helpful discussions, and Dr. R. Kuhn for sharing unpublished data of the human $P_{0}$ promotor sequence. Vimentin and GFAP cDNAs were kindly provided by Dr. G. Weinmaster; a mouse MBP clone, by Dr. A. Roach (University of Toronto); and a rat CNP cDNA clone, by Dr. D. Colman (Columbia University). This work was supported by grants from the NIH and the National Multiple Sclerosis Society. K.A.N. is a postdoctoral fellow of the National Multiple Sclerosis Society. G.L. is an awardee of the Pew Scholars Program of the Pew Charitable Trusts and of the Basil O'Connor Starter Scholars Program of the March of Dimes Foundation.

Correspondence should be addressed to Dr. Klaus-Armin Nave, Zentrum für Molekulare Biologie, Universität Heidelberg, Im Neuenheimer Feld 282, D-6900 Heidelberg, Germany.

Copyright (c) 1991 Society for Neuroscience $0270-6474 / 91 / 113060-10 \$ 05.00 / 0$
}

cursor $(\mathrm{O}-2 \mathrm{~A})$ cells, when maintained in serum-free medium, exit the cell cycle and differentiate into oligodendrocytes. This process marks their default pathway of development (reviewed by Raff, 1989). Commitment of precursor cells to the oligodendroglial lineage is then followed by activation of the major myelin genes (e.g., those encoding PLP and MBP). Although studies of cultured glial stem cells have provided important insights into the factors that regulate their development, these precursors are difficult to isolate in the large quantities required for biochemical analyses of gene regulation. We have therefore investigated the ability of a clonal glial cell line to "differentiate" in culture and express myelin-specific genes, and have focused on the gene encoding PLP, a $30 \mathrm{kDa}$ integral membrane protein and major structural component of CNS myelin (Lees and Brostoff, 1984; Nave and Milner, 1989). Ideally, a cell line transcribing the PLP gene should serve both as an in vivo system for the characterization of cis-regulatory elements in this gene, and as a source of the corresponding trans-acting factors.

Only a few established cell lines are known to have oligodendroglial properties, and no glial cell line is presently known to express all of the myelin-associated genes that are transcribed in differentiated oligodendrocytes. The rat glioblastoma line $\mathrm{C} 6$, one of the first glioma lines adapted to culture (Benda et al., 1968), expresses a repertoire of enzymatic activities (Volpe et al., 1975; McMorris, 1977; Kumar et al., 1984) that are characteristic of both astrocytes and oligodendrocytes. C6 cells may therefore have derived from the transformation of a common precursor cell of the macroglial cell lineage. In this respect, these cells are related to the bipotential O-2A glial stem cells of the rat optic nerve (Raff et al., 1983). We show here that C6 cells that differentiate in culture induce high-level expression of the PLP gene. In exponentially growing cells cultured with frequent changes of serum-containing media, PLP mRNAs are virtually absent; following growth arrest at high cell density or in serumfree medium, the PLP gene is induced. Using this system, we characterize the promotor region of the rat PLP gene and find that transcriptional activation of PLP in C6 cells is regulated by elements located within a $1 \mathrm{~Kb}$ region upstream of exon $\mathrm{I}$. We identify multiple nuclear protein binding sites in this region: one of these binding sites contains a sequence element that is also found in the 5 ' regulatory regions of the MBP, MAG, and $P_{0}$ genes. This raises the possibility that common trans-acting factors are involved in the coordinate expression of the major myelin proteins.

\section{Materials and Methods}

Cell culture. Rat C6 glioblastoma cells and mouse NIH3T3 fibroblasts were obtained from American Type Culture Collection and grown on plastic petri dishes with Dulbecco's modified Eagle's medium (DMEM; 


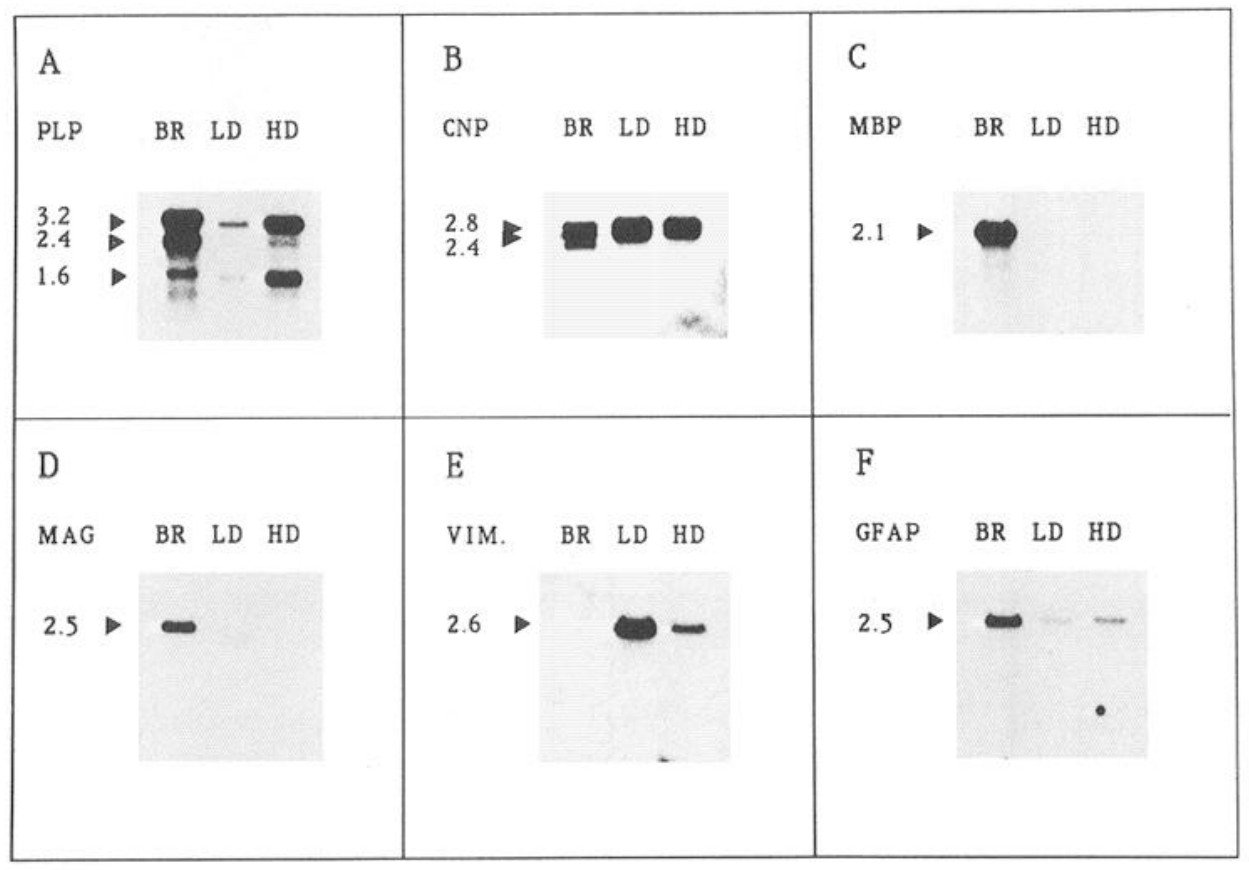

Figure 1. Expression of glial-specific genes in brain and C6 glioblastoma cells. In each Northern blot, $2.0 \mu \mathrm{g}$ of polyA ${ }^{+}$ RNA of 4-week-old mouse brain $(B R)$ is compared to the same amount of polyA ${ }^{+}$RNA from rat $\mathrm{C} 6$ cells, harvested either at low cell density $(L D)$ or at high cell density (HD) (see Fig. 2). Blots were hybridized to ${ }^{32} \mathrm{P}$-radiolabeled CDNA probes encoding the following proteins: $A$, PLP; $B, C N P$; $C$, MBP; $D$, MAG; $E$, vimentin; $F$, GFAP. The size difference between rat and mouse PLP mRNAs results from alternative use of polyadenylation signals (Nave et al., 1986). Equal loading of RNA was verified both by methylene blue staining and by reprobing the blots for expression of elongation factor EF1 $\alpha$-mRNA (not shown).

GIBCO) containing 10\% fetal calf serum (FCS; GIBCO), $100 \mathrm{U} / \mathrm{ml}$ penicillin, and $100 \mu \mathrm{g} / \mathrm{ml}$ streptomycin. Where indicated, forskolin (Calbiochem) was added to $20 \mu \mathrm{M}$ final concentration and $12-O$-tetradecanoylphorbol 13-acetate (TPA; Sigma) to $100 \mathrm{ng} / \mathrm{ml}$.

Northern blot analysis. Total RNA was isolated using the guanidine thiocyanate/water-saturated phenol procedure of Chomczynski and Sacchi (1987). Total RNA $(5 \mu \mathrm{g})$ or polyA+-selected RNA $(2 \mu \mathrm{g})$ was fractionated on $1.0 \%$ agarose gels in $1 \mathrm{M}$ formaldehyde, transferred to Nytran membranes (Schleicher and Schüll, Keene, NH), and hybridized with ${ }^{32} \mathrm{P}$-labeled probes in $50 \%$ formamide, $0.75 \mathrm{M} \mathrm{NaCl}, 25 \mathrm{~mm}$ 1,4-piperazinediethanesulfonic acid (PIPES) (pH 6.8), 0.2\% SDS, 25 mм EDTA, $100 \mu \mathrm{g} / \mathrm{ml}$ salmon sperm DNA, and $5 \times$ Denhardt's solution at $42^{\circ} \mathrm{C}$ overnight. Probes were generated by random prime labeling the inserts of cDNA clones of rat PLP (Milner et al., 1985), mouse MBP (Roach et al., 1983), rat MAG (Lai et al., 1987), rat CNP (Bernier et al., 1987), rat vimentin, and rat glial fibrillary acidic protein (GFAP) (D. Feinstein, G. Weinmaster, and R. Milner, unpublished observations). Blots were washed twice in $2 \times$ saline-sodium citrate (SSC) $/ 0.5 \%$ SDS and once in $0.4 \times \mathrm{SSC} / 0.2 \% \mathrm{SDS}$ at $65^{\circ} \mathrm{C}$ and exposed to Kodak X-AR film at $-70^{\circ} \mathrm{C}$ with Cronex Lightning Plus intensifying screens for 12-24 hr.

Cloning, sequence analysis, plasmid construction. The rat PLP gene was isolated from a genomic library in $\lambda$-Charon $4 \mathrm{~A}$, using the PLP cDNA clone p27 as a probe (Milner et al., 1985). A 1.3-Kb EcoRI fragment containing the promotor region was subcloned into pUC18, nested deletions were generated with exoIII/mung bean nuclease (Stratagene), and the nucleotide sequence was determined by the chain termination method using a Sequenase kit (U.S. Biochemical Co.). The 1188-base pair (bp) EcoRI-BamHI promotor fragment was cloned into the polylinker upstream of the chloramphenicol acetyltransferase (CAT) gene in pBLCAT3 (Luckow and Schütz, 1988), generating clone CAT1038. A series of $5^{\prime}$ deletions of CAT-1038 was generated with exoIII/ mung bean nuclease, and the position of each $5^{\prime}$ end was determined by sequence analysis. The numbering of the deletion clones refers to the position of their respective $5^{\prime}$ ends relative to the first transcription start site of the rodent PLP gene (Milner et al., 1985; Ikenaka et al., 1988), except for CAT-77, which is labeled with reference to the most 3 ' transcription start site at +74 . A $1.38-\mathrm{Kb}$ HindIII-BspM2 fragment of the mouse MBP gene (Takahashi et al., 1985) was ligated into the HindIII and Xmal site of pKS + (Stratagene), excised with HindIII and BamHI, and religated into the upstream polylinker of pBLCAT3. Plasmid DNAs were purified on cesium chloride gradients.

Transfections and CAT assays. Calcium phosphate-mediated transfections $(10 \mu \mathrm{g}$ per $60 \mathrm{~mm}$ plate) were performed as described by Graham and van der Eb (1973) and Wigler et al. (1979). Cells were either plated at $4 \times 10^{3} / \mathrm{cm}^{2} 1 \mathrm{~d}$ before transfection and harvested $2 \mathrm{~d}$ later (protocol 1) or plated at $4 \times 10^{4} / \mathrm{cm}^{2}$ and harvested 3-4 d after trans- fection (protocol 2). To ensure induction of the PLP gene at high density, cultures that had not reached confluence by $72 \mathrm{hr}$ after transfection were discarded. Transfection efficiency was monitored by cotransfecting a luciferase expression construct $(3 \mu \mathrm{g})$ driven by either the SV40 early promotor (deWet et al., 1987) or by the promotor of the rat PLP gene. C6 cells stably transfected with CAT- 1038 were obtained by cotransfecting $1.0 \mu \mathrm{g}$ pRSVneo (Gorman et al., 1983) and selecting clones in the presence of $400 \mu \mathrm{g} / \mathrm{ml} \mathrm{G} 418$ (GIBCO). Chloramphenicol acetyltransferase (CAT) activity was determined in cell extracts by the method of Gorman et al. (1982) and was normalized to transfection efficiency. After thin-layer chromatography and autoradiography, acetylated and nonacetylated ${ }^{14} \mathrm{C}$-chloramphenicol was quantitated in a scintillation counter. Mean and standard deviations of chloramphenicol conversion rates were calculated from the results of three separate experiments.

Analysis of DNA binding proteins. Nuclear protein extracts from $10^{\circ}$ C6 cells and 3T3 cells grown to high density were prepared as described by Ohlsson and Edlund (1986) and as modified by Christy et al. (1989). Brain nuclear extracts from 4-week-old $\mathrm{Balb} / \mathrm{c}$ mice were prepared by the method of Gorski et al. (1986). All protein extracts were dialyzed twice against a buffer containing $25 \mathrm{~mm}$ HEPES (pH 7.6), $40 \mathrm{~mm} \mathrm{KCl}$, $0.1 \mathrm{~mm}$ EDTA, $1 \mathrm{~mm}$ dithiothreitol (DTT), $0.1 \mathrm{~mm}$ phenylmethylsulfonyl fluoride (PMSF), and 10\% glycerol. End-labeled restriction fragments were generated with DNA polymerase I (Klenow) utilizing the following restriction sites in the rat PLP promotor: EcoRI $(-1043)$, AluI $(-570)$, NcoI $(-435)$, DraI $(-291)$, XbaI $(-192)$, HindIII $(-184)$, HinfI $(-112)$, and BamHI $(+86)$. DNase I protection analysis $(20,000$ $\mathrm{cpm}$ probe) with $2.0 \mu \mathrm{g}$ poly-dIdC competitor DNA and up to $90 \mu \mathrm{g}$ of nuclear protein extract was carried out as described by Mangalam et al. (1989).

\section{Results}

Expression of myelin-specific genes by C6 cells

We initially analyzed C6 cells for the expression of several myelin-specific genes. As shown in the Northern blots of Figure 1, mRNAs characteristic of both astrocytes and oligodendrocytes were present. However, the abundance of some mRNAs was strongly influenced by the cell density at the time of harvest (Fig. 2). In particular, expression of PLP mRNA was markedly increased after $\mathrm{C} 6$ cells reached confluence. In high-density cultures, the level of PLP mRNA approached that of adult mouse brain (Fig. 1A). In contrast, in exponentially growing C6 cells, expression of PLP mRNA was very low and was nearly unde- 
Figure 2. C6 cell density at time of RNA isolation. Photomicrograph of C6 cells exponentially growing at low cell density $(A)$, with extensive cell contact but not confluent (medium density) $(B)$, and confluent at high density $(C)$. Magnification, $1000 \times$.

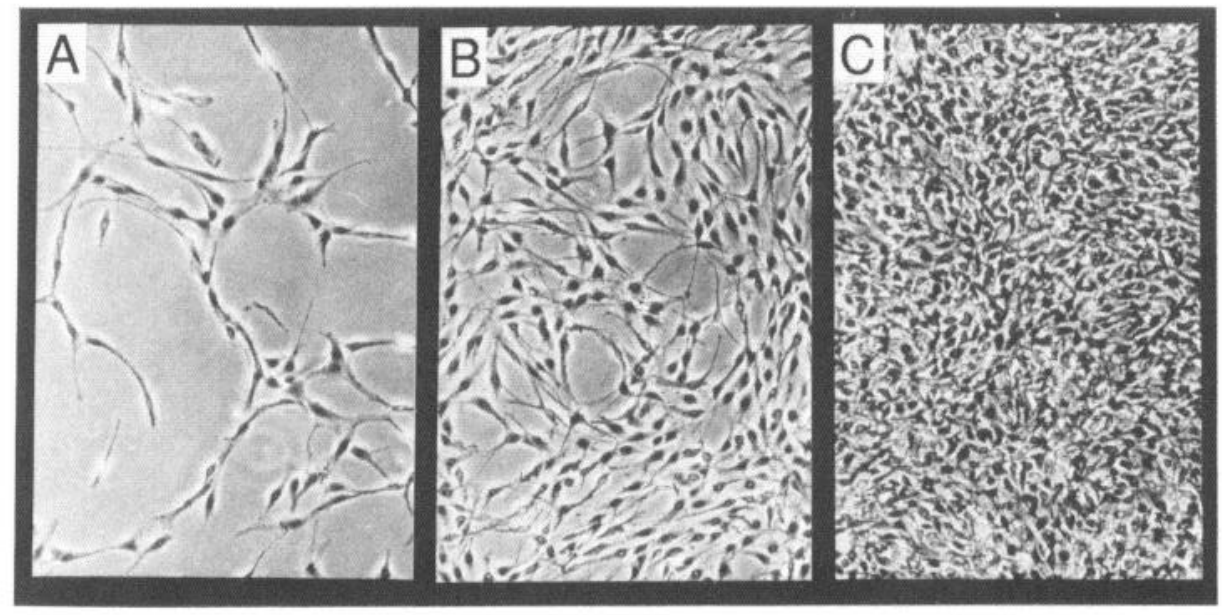

tectable when the culture medium was changed daily (Fig. $3 A$, lane b). MBP and MAG mRNAs could not be detected under any culture conditions tested (Fig. $1 C, D$ ), but transcripts of the gene encoding the enzyme CNP, an early oligodendrocyte marker, were equally abundant at both low and high cell density (Fig. $1 B$ ). In agreement with previous immunohistochemical data (Raju et al., 1980), we found low levels of GFAP mRNA in C6 cultures, indicating the presence of astrocyte-like cells, but we did not observe a significant change in its abundance in confluent as opposed to rapidly growing cells (Fig. $1 F$ ). The abundance of vimentin mRNA, often used as a marker for glial precursor cells and astrocytes (Schnitzer et al., 1981), was significantly downregulated at high cell density (Fig. 1E).

\section{Induction of PLP $M R N A$ by cell contact and cAMP}

As noted above, PLP mRNA was barely detectable in C6 cells cultured at low density in serum-containing medium that was changed daily. Induction of the PLP gene in response to serum removal or high culture density appeared to be an intrinsic property of C6 cells, since a $24 \mathrm{hr}$ incubation with medium conditioned by confluent cells did not induce PLP expression in cells cultured at low density (data not shown). Moreover, when FCS was removed from the medium for $24 \mathrm{hr}$, significant amounts of PLP mRNA could be detected even in cells cultured at low density (Fig. 3A, lane c), and the abundance of PLP mRNA in cells at high density was further increased by serum removal. The dramatic increase in steady-state PLP mRNA levels observed upon switching C6 cells from low cell density in $10 \%$ FCS to high cell density in serum-free medium was reversible (not shown).

To determine whether the inducing effect of cell-cell contact involves a known second-messenger system, we added the protein kinase $\mathrm{C}$ activator TPA and the adenylate cyclase activator forskolin to cultures of exponentially growing or confluent C6 cells. As shown in Figure $3 B$, neither agent induced PLP mRNA over control after $3 \mathrm{hr}$ of treatment, but after $20 \mathrm{hr}$ a significant induction of PLP mRNA was observed in cells cultured at low density and treated with forskolin (Fig. $3 C$ ). The $20 \mathrm{hr}$ forskolin stimulation did not significantly increase PLP mRNA in cultures that had already reached confluence.

\section{Transcriptional activation of the PLP gene}

We isolated genomic clones of the rat PLP gene from a rat genomic library (Nave et al., 1987). A 1125 bp EcoRI-BamHI fragment from the $5^{\prime}$ end of this gene was sequenced (Fig. 4) and ligated upstream of the bacterial CAT reporter gene in the vector pBLCAT3 (Luckow and Schütz, 1988). This fragment contains the presumptive PLP promotor region, including four identified transcription start sites and much of the 5 ' untranslated region (Milner et al., 1985; Ikenaka et al., 1988; Boison and Stoffel, 1989).

When this hybrid reporter plasmid (CAT-1038) was transiently transfected into rapidly proliferating C6 cells using a standard calcium phosphate precipitation protocol (Wigler et al., 1979), CAT expression was very low compared to the signal obtained when the same CAT gene was driven by the SV40 early promotor (Fig. 5). However, when the transient transfection protocol was modified to allow $\mathrm{C} 6$ cells to reach and maintain high density after transfection (protocol 2 in Fig. $5 A$ ), the specific CAT activity of cellular extracts increased by more than an order of magnitude. Unfortunately, it was impossible to compare directly the absolute CAT activities obtained with these two transfection protocols due to the decrease in transfection efficiency observed at high cell density, and the presumed accumulation of CAT protein and loss of template DNA with time. Nonetheless, growth arrest conditions that induced abundant expression of the endogenous PLP gene also strongly potentiated expression of the transfected PLP promotor-CAT gene. These growth arrest conditions did not potentiate expression of a transfected reporter construct in which transcription of the CAT gene was driven by the SV40 early promotor. We obtained results comparable to these in a $\mathrm{C} 6$ subline stably transfected with clone CAT-1038. Growth to either low, medium, or high density as defined in Figure 2, the specific CAT activity in cell extracts (per microgram of soluble protein) was increased over 10 -fold in confluent cells (Fig. $5 B$ ), in close agreement with the observed induction of the endogenous PLP gene.

To determine whether transfection protocol 2 might also be used to study the regulation of other myelin-specific genes in C6 cells, we placed the CAT gene under the control of a 1380 bp 5 ' flanking HindIII-BspM2 fragment from the mouse MBP gene (Takahashi et al., 1985). Even though expression of the endogenous MBP gene was never detected in C6 cells cultured at either low or high density (Fig. 1), we observed a strong MBPCAT signal, comparable to that obtained with the PLP clone CAT-1038, in transiently transfected C6 cells (data not shown). No MBP promotor-driven CAT activity was observed in transfected NIH3T3 fibroblasts. 


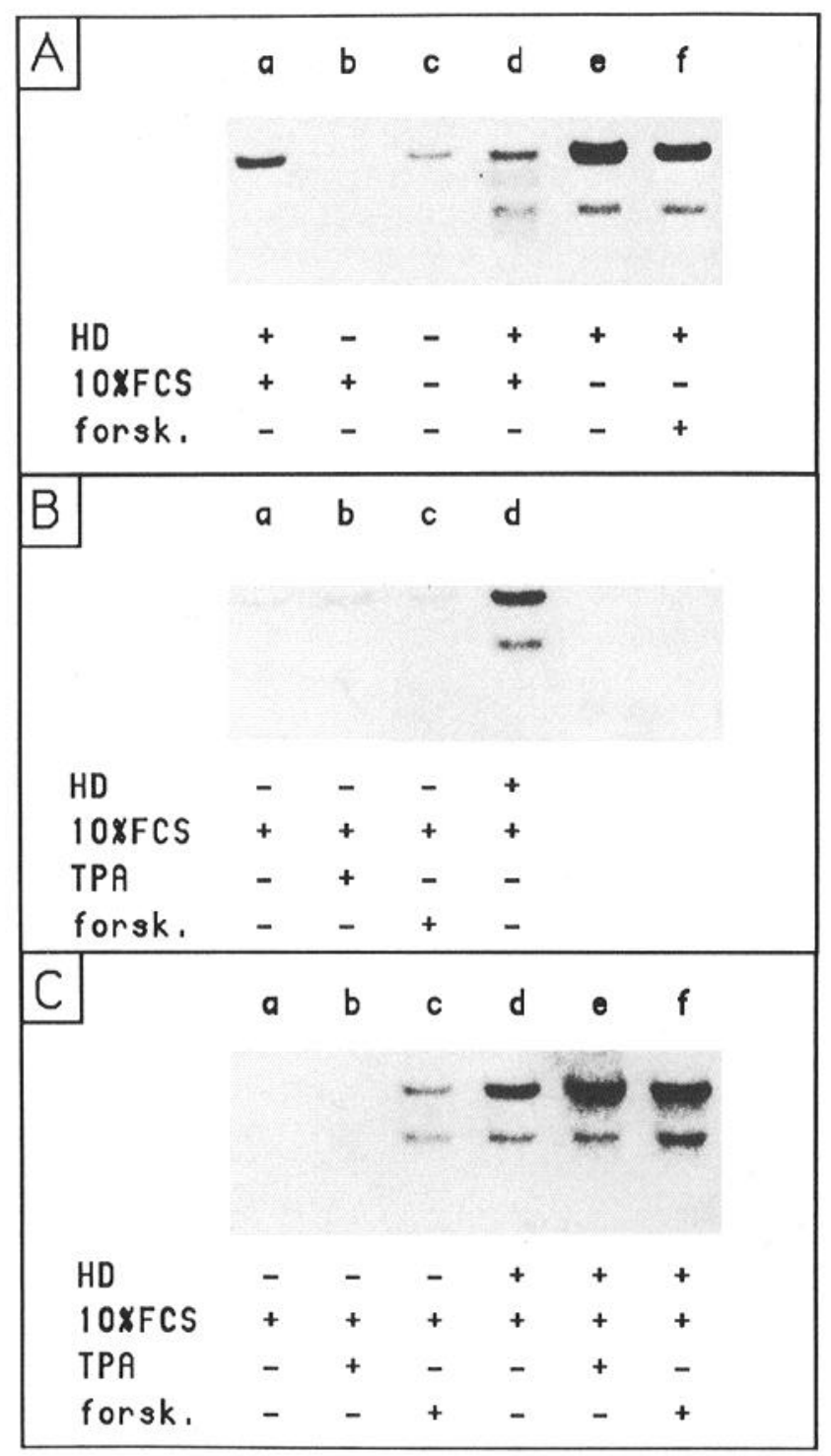

Figure 3. Induction of PLP mRNA in C6 cells by cell contact, serum removal, and increased intracellular cAMP. Five micrograms of total RNA were size fractionated, and Northern blots were probed with a rat PLP cDNA. Equal loading of RNA was verified by methylene blue staining (not shown). A, C6 cells were grown in the presence of $10 \%$ FCS (lanes $a, b$, and $d$ ) or without serum (lanes $c$, $e$, and $f$ ) for $24 \mathrm{hr}$, and harvested at low cell density (lanes $b$ and $c$ ) or high cell density (lanes $a, d-f$ ). Induction (lane $c$ ) and enhancement (lanes $e$ and $f$ ) of PLP mRNA were observed in serum-free medium. Addition of $20 \mu \mathrm{M}$ forskolin (forsk; lane $f$ ) to serum-free medium did not further increase PLP mRNA. B, C6 cells were grown in the presence of $10 \%$ FCS at low cell density (lanes $a-c$ ) or high density (lane $d$ ) and supplemented with either TPA (lane $b$ ) or forskolin (lane $c$ ) for $3 \mathrm{hr}$ prior to harvest. $C$, Same as in $B$, but the treatment was extended to $20 \mathrm{hr}$. Cells were grown to low density (lanes $a-c$ ) and high density (lanes $d-f$ ) in the presence of TPA (lanes $b$ and $e$ ) or forskolin (lanes $c$ and $f$ ).

\section{The PLP gene contains positive and negative regulatory} elements

To identify the position of transcriptional control elements, we progressively truncated the $5^{\prime}$ regulatory region of the PLP gene in a $5^{\prime}$ to $3^{\prime}$ direction from position -1038 and placed these promotor deletions upstream of the CAT reporter gene (Fig. 6). In these experiments, transient expression of the deletion clones was first studied in induced C6 cells at high density (transfection
ECORI

CTGCAGGTCG ACGGTATCGA TAAGCTTGAT ATCGAATTCC CAAAGTTTAC

-1027 AGTCAGTTCT ITTTGCCATC ACCCCTCTCC TCCTGGGCCA TCAATATARA

- 977 GataAtCCCA CAGCTGCACt tTCGTARCAg GCAgaAtCTG tGTCtTGagG

- 927 GCagtcctag gahggcatgg gtcttagatc ctchacagtc agtcatggcc

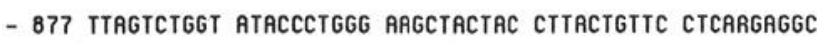

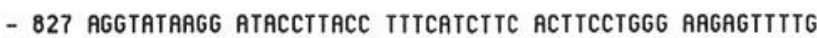

- 777 ACTGGCTGAT TTCCAGTtTG TGATARTGTT TIGTCTCARA GTACATITTC

- 727 CTTGGaARTC ACCTACATGT TCCACTCTTG CCATCTITTT TCCTTGTGAC

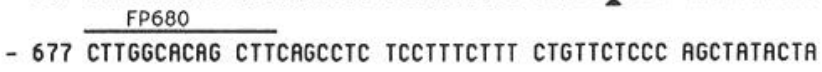

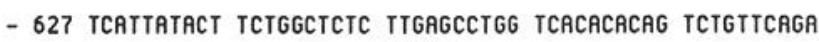
- 577 GACTTAGCTG CTTGTITTAT CGTCATTCTT CTGAAAGCAR RGGTTTTGRA

- 527 GAAATTATTT TAAATGACAR CTTTTCCTTC CCTATTGTGT TICCAGGGCA

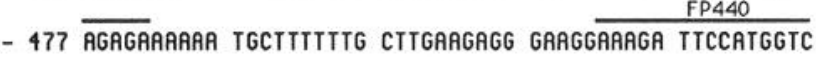

- 427 AAGGCCAACT AACAGTGAGT GITGGGTGGG GCATGILTGG TAATATAGCA

- 377 AGTAGGGTTT ATGATCCAGA TCCCCTCCTC ACCAGGGCTA CCATTTCACA

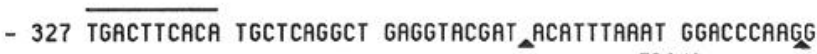
FP240

- 277 ACAATTTGGG AGGATITAAG GACCCCTCCA CTTAATTTCC ACCCACARTT

- 227 TACATTTCAT GaTTCATtTA TATCAAARTG AaATTCTAGR GAAGCTTTGG

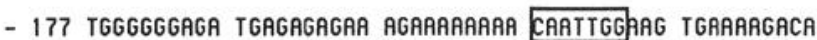

FPI10

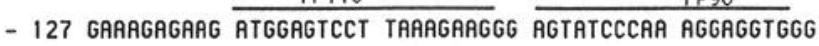
FP70

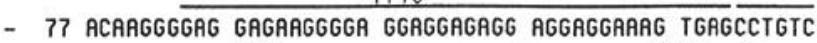

$\stackrel{\text { FP2O }}{\longrightarrow}$

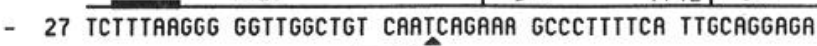

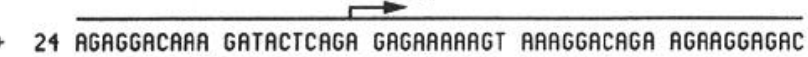
$\Longrightarrow \quad$ BamHI

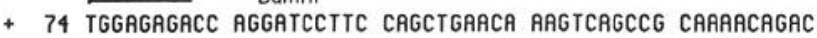

Fintron 1

+ 124 tagccagcag gctoCaAtTg Gagccagagt gCcaAagac atgGgtgagtT

Figure 4. Sequence of the 5 ' flanking region and exon 1 of the rat PLP gene. Transcription start sites previously identified by primer extension analysis (Milner et al., 1985; Ikenaka et al., 1988) are marked by arrows; the most $5^{\prime}$ site is defined as +1 . Putative TATA $(-23)$ and CAAT elements $(-139,+138)$ are indicated. DNase I-protected binding sites of $\mathrm{C} 6$ glial nuclear proteins are marked by horizontal lines on top of the nucleotide sequence. The $5^{\prime}$ ends of deletion clones are indicated by arrowheads. The Bam $(+87]-$ EcoRI $(-1038)$ fragment of the rat PLP gene was cloned into the CAT expression vector pBLCAT-3 (Luckow and Schütz, 1988) generating clone CAT-1038.

protocol 2). Since the expression of CAT-1038 was severely influenced by culture conditions (cell density, serum factors), minor variations between individual cultures might easily mask the effect of single regulatory elements on promotor activity. To control for these variations and for overall transfection efficiencies, we cotransfected for each deletion point a plasmid containing the firefly luciferase gene (deWet et al., 1987) under the control of the 1038 bp rat PLP promotor. All CAT assays were thus normalized to the activity of clone CAT-1038 in this system, and the chloramphenicol conversion rates for deletion clones 
A

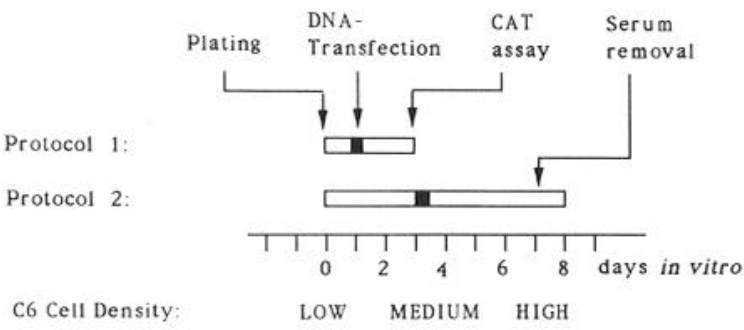

B

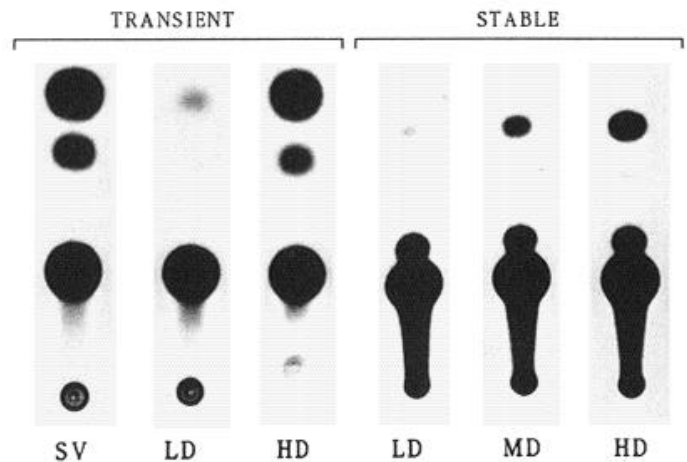

Figure 5. High cell density induces PLP gene transcription in transfected C6 cells. $A$, In transfection protocol 1 , C6 cells were plated at low density and harvested $2 \mathrm{~d}$ after calcium phosphate-mediated DNA transfection. In protocol 2, cells were plated at medium density and harvested $4 \mathrm{~d}$ after transfection ( $24 \mathrm{hr}$ after reaching confluence). B: Left, Transient CAT expression in C6 cells. Construct CAT-1038 (lane $L D$ ), transfected following protocol 1 , was compared to the same CAT gene driven by the SV 40 promotor (lane SV) and to CAT-1038 transfected following protocol 2 (lane $H D$ ). CAT activity was determined for equal amounts of luciferase activity in the extract. Right, CAT-1038 was stably transfected in C6 cells, and specific CAT activity ( $1 \mu$ g protein) was compared in a subclone harvested at low $(L D)$, medium $(M D)$, or high $(H D)$ density as defined in Figure 2.

shown in Figure 6 were normalized to equal luciferase activity. Actual conversion rates were always in the linear range of the CAT assay. This normalization protocol results in a level of PLP promotor competition that can be accurately estimated and that does not prevent detection of transcriptional control elements.

A striking result from this analysis was that the transcriptional activity of some deletion clones was significantly higher in the absence rather than the presence of their respective $5^{\prime}$ flanking fragments (Fig. 6). Specifically, sequences immediately upstream of $-186,-391$, and -690 had a negative effect on the transcriptional activity of the CAT construct, while positive $\mathrm{cis}$ regulatory elements were located between -391 and -297 , and between -690 and -480 . A 10 -fold drop in promotor activity observed upon deletion of sequences immediately upstream of the core promotor was likely the consequence of an inactivated CCAAT box in clone CAT-146 (see below). All results are the mean of at least three separate experiments, and SDs have been indicated in parentheses. These data strongly suggest that the activity of the induced PLP promotor is controlled by both positive and negative cis-regulatory elements.

We next introduced the same set of deletion clones into C6 cells maintained at low density (following protocol 1) to test the possibility that negative regulatory elements might be involved in the repression of PLP transcription at low cell density. Be- cause the level of PLP promotor-driven transcripts were anticipated to be quite low in these transfections, we normalized CAT activity to luciferase activity by cotransfecting a plasmid in which transcription of the luciferase gene was driven constitutively by the SV40 early promotor. We found that the level of CAT activity obtained with protocol 1 was more than one order of magnitude lower than the level obtained using transfection protocol 2 and that for the most part this reduction in transcriptional activity was observed throughout the deletion series (Fig. 6). That is, we observed no specific "derepression" of the PLP promotor by the removal of any 5 ' flanking sequence that was not also apparent in C6 cells maintained at high cell density. The deletion of upstream fragments caused a similar modulation of the base line promotor activity normalized to $100 \%$ for the CAT- 1038 construct in both transfection protocols. A notable exception was the lack of transcriptional repression observed for sequences upstream of CAT-186, which was only seen in C6 cells cultured at high cell density (Fig. 6). At high cell density, the strongest CAT activity was observed with clone CAT-186 (16-fold over baseline activity), while at low cell density, CAT-391 gave the strongest signal (threefold over baseline activity).

\section{The PLP regulatory region contains multiple binding sites for C6 nuclear proteins}

The regulated expression of the PLP gene in C6 cells suggested to us that these cells might be useful for the identification of trans-acting factors that control the expression of this gene. Inspection of the nucleotide sequence of the rat PLP promotor between positions -1038 and +200 revealed only a few sites with homology to sequences of known protein binding sites (Wingender, 1988). A putative TATA element (TTTAA) is located 23 bp upstream of the first transcription start site, but no such sequence precedes the remaining start sites at $+16,+43$, and +74 (Fig. 4 ; with the most $5^{\prime}$ transcription start site defined as +1 , the initiation codon occurs at +164 ; Milner et al., 1985; Macklin et al., 1987; Ikenaka et al., 1988). One CCAAT element $\left(5^{\prime}\right.$-CAATTGG- $\left.3^{\prime}\right)$ resides in an antisense orientation at position -147 , and the same 7 bp element is found in the first exon at position +138 .

That regulatory sequences upstream of the PLP promotor are recognized by the same DNA binding proteins present in nuclear extracts prepared from brain and C6 cells was first suggested by gel mobility shift experiments (not shown). Using nuclear extracts prepared from high density C6 glioblastoma cells and PLP-negative NIH3T3 fibroblasts, we then identified individual DNA binding sites using DNase I footprinting procedures. Between position -700 and exon I, we determined the positions and sequences of 14 protein binding sites, 8 of which are illustrated in the representative footprints of Figure $7 \mathrm{~A}$. The complete set of sites we identified is schematically summarized in Figure $7 B$. Strong protection by glial nuclear proteins was observed for the area surrounding the multiple transcription start sites, including sequences encoding the $5^{\prime}$ untranslated region of the PLP mRNA. Sequences immediately $5^{\prime}$ to the transcription start sites were recognized by proteins in both glial and nonglial nuclear extracts. Further upstream in the PLP gene, several protein binding sites were identified, none of which appeared to be identical with previously described regulatory elements. Two distal footprints (FP330 and FP240) contained sequence repeats within the protected region, which might represent tandem binding sites. For example, the sequence $5^{\prime}$ - 


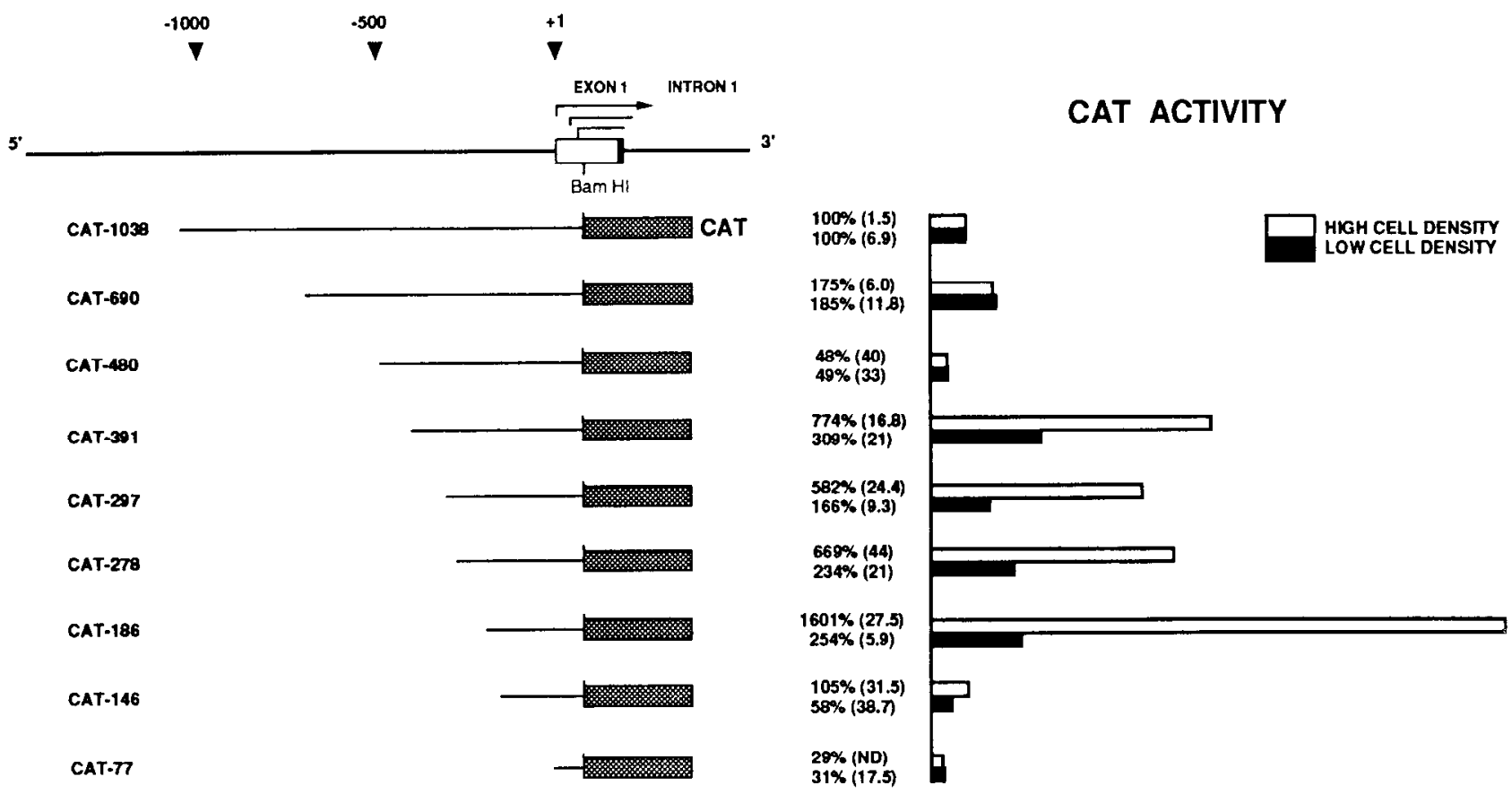

Figure 6. Deletion analysis of the PI.P promotor region reveals positive and negative regulatory elements. C6 cells were transiently transfected with CAT-1038 and $5^{\prime}$ deletion clones, and CAT activities were determined at either low cell density (solid bars) or high cell density (open bars). For each construct, CAT activity has been indicated as the percentage of the value obtained for clone CAT-1038 $(=100 \%)$, normalized for the cxpression of the luciferase gene driven by the SV40 early promotor (at low cell density) and by the PLP promotor (at high cell density). Results are the mean of three separate experiments, and the coefficient of variation (SD $\times 100 /$ mean) is shown in parentheses.

AYTTCACATG- 3 is repeated within FP330. By footprint analysis, the corresponding binding proteins appear much more prominent (per microgram of extract) in $\mathrm{C} 6$ cells than in extracts prepared from 3T3 fibroblast nuclei. Similarly, in FP240 the sequence $5^{\prime}$-AATTTCCAC- $3^{\prime}$ is followed in tandem by the sequence 5'-AATTTACAT-3', which resembles the "octamer" motif (5'-ATTTGCAT-3', Hatzopoulos et al., 1988) and the binding site of the POU domain transcription factor Pit-1 (5'T/A T/A TATNCAT-3'; Nelson et al., 1988).

Although the function of the DNA binding proteins responsible for these footprints is presently unknown, a correlation between the position of a binding site and the result of its deletion from the CAT reporter construct can be made. For example, FP330, FP520, FP560, and FP680 are located with cis-regulatory regions whose deletion resulted in a loss of PLP promotor activity. FP440 and FP240, on the other hand, arc the only DNase-protected sequences in regions that we have tentatively identified as negative regulatory elements.

\section{Homology to the $M B P$ and $P_{0}$ promotors}

A computer search for homology between nuclear protein binding sites of the PLP promotor and the $5^{\prime}$ flanking sequences of other myelin-specific genes revealed two sites in the PLP gene, FP330 and FP12, with extended homology to elements in the MBP promotor (Fig. 8). FP330 was the only footprinted sequence in the positive regulatory region between -297 and -391. For this footprint, the rat PLP gene (FP330) and its equivalent mouse sequence (Ikenaka et al., 1988) are identical in 30 of 32 nucleotides and include a 13 bp motif $A$ ( $5^{\prime}-\mathrm{TCA}$ CATGACTTYA-3'; open box in Fig. 8B). However, the homology of the footprinted area between the rodent and the human PLP gene (Hudson et al., 1989) is low, with only 20 of 32 nucleotides preserved. The human PLP gene instead contains motif B (5'-GGGCTCTCA-3'; shaded box in Fig. 8B) immediately $5^{\prime}$ to motif A. Motif B is also found in the $5^{\prime}$ flanking region of the rodent MBP gene (Miura et al., 1989). Surprisingly, motif $B$ has not been preserved in the human MBP gene (Boylan et al., 1990), and in the equivalent position of this gene motif $A$ is present. Thus, in comparing the rodent and human PLP and MBP genes, the consensus motifs $A$ and $B$ appear to substitute for each other. As shown in Figure $8 B$, the homology of motif $B$ between the PLP and MBP genes extends to the promotors of the rodent and human $P_{0}$ genes (Lemke et al., 1988; R. Kuhn, personal communication) and the rat MAG gene (D. Montag and R. Milner, personal communication). Whether the $\mathrm{A}$ and $\mathrm{B}$ sequences are, in fact, transcriptional regulators of myelin-specific genes, and thus recognized by common transacting factors, awaits further investigation.

\section{Discussion}

Myelin gene expression in a glial progenitor cell line

Like the expression of many neuronal genes in the CNS, the transcription of myelin genes in oligodendrocytes is restricted to postmitotic cells. Lacking a suitable in vivo system, the mechanisms regulating myelin genes during CNS development are unknown. We found that rat $\mathrm{C} 6$ glioblastoma cells exhibit regulated expression of the PLP gene. Abundant transcription of this gene was only observed under growth arrest conditions of high cell density and serum-free culture, and not during exponential growth. As noted above, it is likely that C6 cells have derived from a glial precursor cell related to or with properties of $\mathrm{O}-2 \mathrm{~A}$ cells and have maintained the potential to express glialspecific differentiation markers. Although the plasticity of $\mathrm{C} 6$ cells cannot be considered a model system for the differentiation of glial progenitor cells, it should be noted that the changing 
A

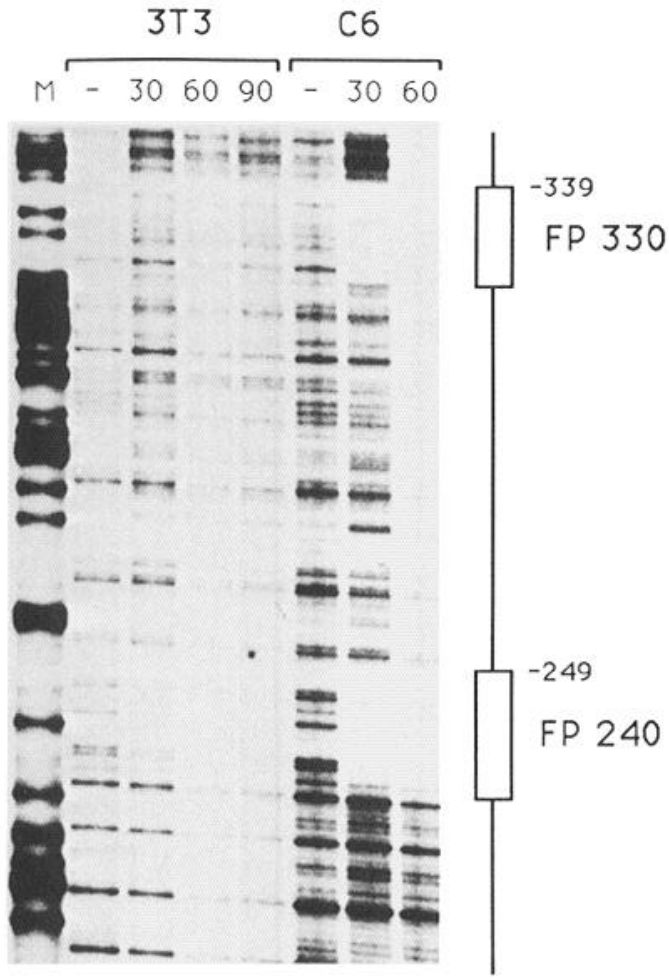

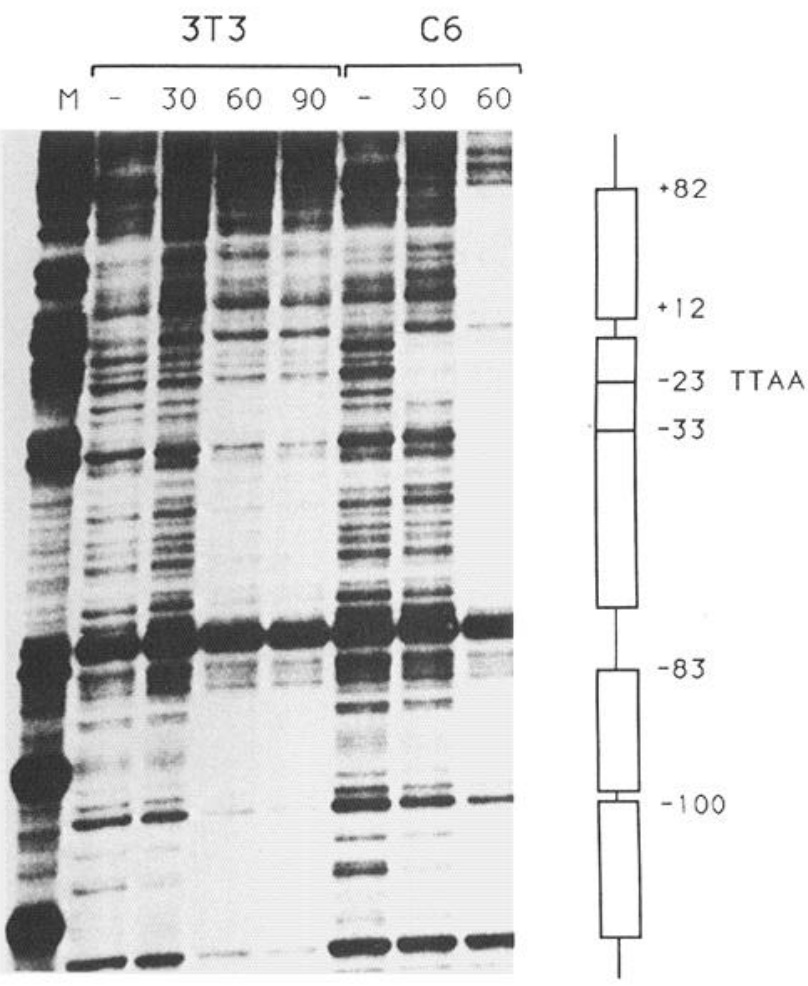

B

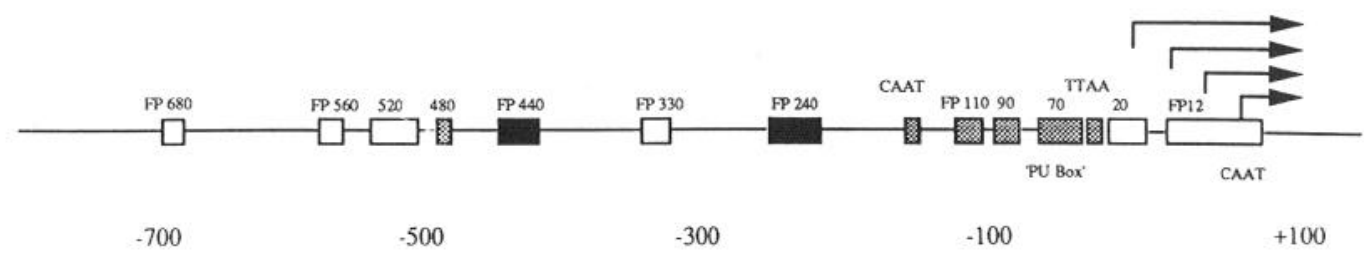

Figure 7. Multiple protein binding sites in the PLP promotor region. A, DNase I footprint analysis of the PLP promotor with nuclear extracts from induced C6 cells and PLP-negative 3T3 cells between -100 and +85 , including the transcription start sites and exon 1 of the PLP gene (right). Examples of DNase I-protected sites distal to the PLP core promotor (FP240 and FP330) are shown on the left. B, Schematic summary of footprint experiments spanning $700 \mathrm{bp}$ of the rat PLP promotor region. The positions of at least 14 distinct binding sites for C6 nuclear proteins were identified (for details, see Fig. 4). Shaded boxes indicate binding sites for proteins that appeared abundant also in 3T3 cell extracts; solid boxes denote putative negative regulatory elements.

pattern of gene transcription in C6 cells at high cell density and upon withdrawal of serum parallels in part the oligodendroglial differentiation of $\mathrm{O}-2 \mathrm{~A}$ cells cultured in serum-free medium (Raff, 1989).

Although high levels of mRNA encoding the myelin-associated enzyme CNP were apparent in C6 cells cultured at either low or high cell density, we were unable to detect the endogenous mRNAs for MBP and MAG, two myelin-specific proteins expressed in terminally differentiated oligodendrocytes, under any culture condition. This observation is consistent with the sequential emergence of myelin gene transcripts in the developing rat brain, which have been detected closely spaced in the temporal order (1) CNP, (2) PLP, and (3) MBP (Kanfer et al., 1989). Alternatively, it is possible that the lack of detectable MBP and MAG mRNAs in C6 cells results from mutations in these genes or from their inactivation by methylation. The presence of a low level of astroglial-specific GFAP mRNA was not unexpected, since a subset of $\mathrm{C} 6$ cells in culture has been reported to stain positive with an antibody for GFAP (Bissell et al., 1975; Raju et al., 1980). However, we noticed only a small change in abundance of GFAP mRNA under those conditions that greatly induced PLP transcription and downregulated vimentin mRNA. Whether the transcription of astroglial and oligodendroglial marker genes is mutually exclusive at the single-cell level awaits a more detailed comparison.

The observation that PLP mRNA abundance in confluent cells is further increased when serum is removed suggests that FCS contains factor(s) that inhibits PLP expression independently of the effect of cell density. Obvious candidates are growth factors such as platelet-derived growth factor (PDGF) and basic FGF (bFGF), which inhibit oligodendroglial differentiation of primary glial stem cells in culture (Richardson et al., 1988; Bögler et al., 1990). A previous attempt to detect high-level expression of PLP mRNA in C6 cells was unsuccessful, possibly because the cells were maintained in the presence of $17.5 \%$ serum and medium was changed daily (Macklin et al., 1986). 


\section{Transcriptional control elements of the PLP gene}

Our primary interest in this study was (1) to analyze the regulation of the PLP gene in a simple cell culture system and (2) to obtain a bona fide source of the DNA binding proteins involved in its transcriptional activation. The PLP gene is also expressed in cultured Schwann cells (Nave et al., 1988); however, the level of transcription is at least 10 -fold lower than in oligodendrocytes. In gene transfer experiments, the cloned PLP promotor was able to drive both transient and stable expression of the CAT reporter gene in C6 cells. CAT expression was highest under the same conditions (high density/low serum) that induce high levels of PLP mRNA in both C6 cells and oligodendrocytes, suggesting that these cells regulate PLP mRNA by induced transcription and that the induction is largely mediated by cis-acting elements contained within the cloned $5^{\prime}$ flanking region of the PLP gene. These data suggest that the regulated expression of CAT-1038 in C6 cells is cell-type specific. This is an important observation, since similar to other cell-type-specific promotors (Sehgal et al., 1988), plasmid CAT-1038 is also "nonspecifically" expressed in some but not all PLP-negative, nonglial cell lines (e.g., 3 T3 cells) (K.-A. Nave and G. Lemke, unpublished observations). In this respect, the specificity of pMBP-CAT expression in C6 cells remains to be determined, since MBP mRNA has not been detected in $\mathrm{C} 6$ cells under any culture condition tested. As noted above, it is possible that DNA methylation or mutation have inactivated the C6 MBP gene.

We used footprint analysis with nuclear extracts from C6 cells maintained at high density to identify the positions and sequences of protein binding sites in the PLP promotor. Unfortunately, the small number of cells that can be harvested from a cell monolayer at "low density" did not permit us to compare directly the footprints from nuclear extracts. The PLP core promotor, including the area surrounding the transcription start sites, was well protected from DNase I digestion, and a determination of the exact number of binding sites must therefore await fractionation of the nuclear extracts. While most of the protected sequences are novel when compared to previously described binding sites in other eukaryotic promotors and enhancers (Wingender, 1988), we noticed that corresponding nuclear DNA binding proteins of some sequences are present in a variety of cell types (Nave and Lemke, unpublished observations). Although transcription factors generally bind sequence specifically, overlapping binding activities and target specificities in vitro have been observed for several genes (Levine and Hoey, 1988). As a clonal cell line, C6 cells might represent a particularly favorable source of transcription factors for the PLP gene. Using these cells, we hope to avoid problems associated with the artifactual mixture of DNA binding proteins present in whole-brain extracts.

When the 5' regulatory region of the PLP gene was progressively deleted, we found that both positive and negative regulatory elements determined the transcriptional activity of the PLP promotor. Negative cis-regulatory elements ("silencers") have been characterized in other cell-type-specific genes (Winoto and Baltimore, 1989; Baniahmad et al., 1990; Mori et al., 1990) and are thought to regulate gene expression by repression and, in combination with positive regulatory elements, by specific derepression. It is possible that downregulated PLP gene transcription in exponentially growing C6 cells as well as the suppressive effect of serum are mediated by such negative cisregulatory elements. However, when normalized to the activity
A

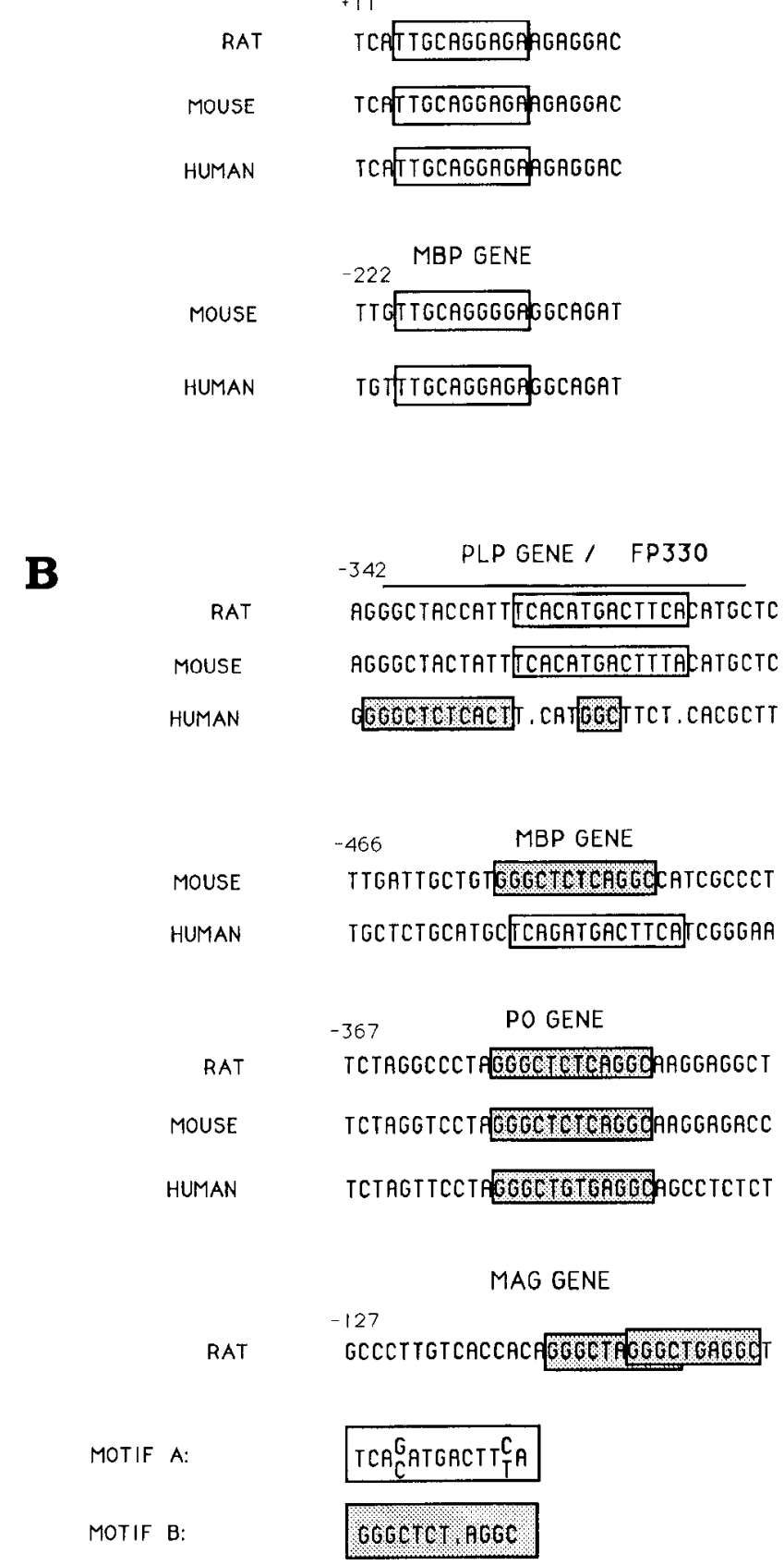

Figure 8. Homology of protein binding sites in the PLP gene to other myelin-specific genes. $A, \mathrm{~A} 10$ bp sequence in FP1 2 of the PLP promotor (+14 to +24 with respect to the most upstream transcription start site) is identical to a sequence element in the gene encoding MBP and is conserved between species. $B$, A 13 bp sequence within FP330 of the rodent PLP gene (open box) is related to an element at a similar position in the human MBP gene (MOTIF A). A second sequence element (shaded box) is found immediately $5^{\prime}$ to MOTIF $A$ in the human PLP gene, is in turn homologous to a sequence at the same position in the rodent MBP gene, and is also found in the myelin genes for rodent and human $P_{v}$ and rat MAG (MOTIF B).

of the "full-length" PLP promotor (clone CAT-1038 in this study), we observed no derepression with any 5 ' deletion of the regulatory region under low-density culture conditions. In contrast, one negative regulatory element located between -278 and -196 (presumably FP240) showed its repressive effect only 
in $C 6$ cells at high density and had no effect on promotor strength when analyzed in proliferating cells.

A sequence in FP330, a footprinted element in a distal PLP regulatory region, is related to sequences found in the genes encoding MBP, $\mathrm{P}_{0}$, and MAG (Fig. 8B). There is evidence from outside the nervous system that functionally related genes contain common $c i s$-regulatory elements. For example, genes encoding the pancreatic enzymes chymotrypsin B, trypsin I, and elastase I share one critical element contained in a DNase I footprint of their 5 ' flanking sequence (Nelson et al., 1990 and citations therein), and the myosin heavy-chain gene, creatine kinase gene, and $\mathrm{ACh}$ receptor genes of developing muscle cells are each regulated by binding of the trans-regulator myoD (Lassar et al., 1989). It is therefore possible that coordinate expression of the major myclin genes in the CNS and PNS is transcriptionally controlled, in part, by common trans-regulatory proteins.

\section{References}

Baniahmad A, Steiner C, Köhne AC, Renkawitz R (1990) Modular structure of a chicken lysozyme silencer: involvement of an unusual thyroid hormone receptor binding site. Cell 61:505-514.

Benda P, Lightbody J, Sato G, Levine L, Sweet W (1968) Differentiated rat glial cell strain in tissue culture. Science 161:370-371.

Bernier L, Alvarez F, Norgard EM, Raible DW, Mentaberry A, Schembri JG, Sabatini DD, Colman DR (1987) Molecular cloning of a 2',3'-cyclic nucleotide 3'-phosphodiesterase: mRNAs with different 5 ' ends encode the same set of proteins in nervous and lymphoid tissues. J Neurosci 7:2703-2710.

Bisscl MG, Eng LF, Herman MM, Bensch KG, Miles LEM (1975) Quantitative increase in neuroglia-specific GFA protein in rat C-6 glioma cells in vitro. Nature 225:633-634.

Bögler O, Wren D, Barnett SC, Land H, Noble M (1990) Cooperation between two growth factors promotes extended self-renewal and inhibits differentiation of oligodendrocyte-type-2 astrocyte $(\mathrm{O}-2 \mathrm{~A})$ progenitor cells. Proc Natl Acad Sci USA 87:6368-6372.

Boison D, Stoffel W (1989) Myelin-deficient rat: a point mutation in exon III $(\mathrm{A} \rightarrow \mathrm{C}$, Thr75 $\rightarrow$ Pro) of the myelin proteolipid protein causes dysmyelination and oligodendrocyte death. EMBO J 8:32953302.

Boylan KB, Ayres TM, Popko B, Takahashi N, Hood LE, Prusiner SB (1990) Repetitive DNA (TGGA) $5^{\prime}$ to the human myelin basic protein gene: a new form of oligonucleotide repetitive sequence showing length polymorphism. Genomics 6:16-22.

Chomczynski P, Sacchi N (1987) Single-step method of RNA isolation by acid guanidinium thiocyanate-phenol-chloroform extraction. Anal Biochem 162:156-159.

Christy RJ, Yang VW, Ntambi JM, Geiman DE, Landschulz WH, Friedman AD, Nakabeppu Y, Kelly TJ, Lane MD (1989) Differentiationinduced gene expression in 3T3-L1 preadipocytes: CCAAT/enhancer binding protein interacts with and activates the promotors of two adipocyte-specific genes. Genes Dev 3:1323-1335.

deWet J, Wood KV, DeLuca M, Helinski DR, Subramani S (1987) Firefly luciferase gene: structure and expression in mammalian cells. Mol Cell Biol 7:725-737.

Gorman CM, Moffat LF, Howard BH (1982) Recombinant genomes which express chloramphenicol acetyltransferase in mammalian cells. Mol Cell Biol 2:1044-1051.

Gorman CM, Padnamhan R, Howard BH (1983) High efficiency transformation of primate cells. Science 221:551-553.

Gorski K, Cameiro M, Schibler U (1986) Tissue-specific in vilro transcription from the mouse albumin promotor. Cell 47:767-776.

Graham FL, van der Eb AJ (1973) A new technique for the assay for the effectivity of human adenovirus 5 DNA. Virology 52:456-467.

Hatzopoulos AK, Schlokat U, Gruss P (1988) Enhancers and other cis-acting regulatory sequences. In: Transcription and splicing (Hames BD, Glover DM, eds), pp 43-96. Washington, DC: IRL.

Hudson LD, Pucket C, Berndt J, Chan J, Gencic S (1989) Mutation of the proteolipid protein (PLP) gene in a human X-linked myelin disorder. Proc Natl Acad Sci USA 86:8128-8131.

Ikenaka K, Furuichi T, Iwasaki Y, Moriguchi A, Okano H, Mikoshiba
K (1988) Myelin proteolipid protein gene structure and its regulation of expression in normal and jimpy mutant mice. J Mol Biol 199:587596.

Kanfer J, Parenty M, Goujet-7alc C, Monge M, Bernier I, Campagnoni AT, Dautigny A, Zalc B (1989) Developmental expression of myelin proteolipid, basic protein, and $2^{\prime}, 3^{\prime}$-cyclic nucleotide $3^{\prime}$-phosphodiesterase transcripts in different rat brain regions. J Mol Neurosci 1: $39-46$.

Kumar S, Weingarten DP, Callahan JW, Sachar K, de Vellis J (1984) Regulation of mRNAs for three enzymes in the glial cell model C6 cell line. J Neurochem 43:1455-1463.

Lai C, Brow MA, Nave KA, Noronha A, Quarles RH, Bloom FE, Milner RJ, Sutcliffe JG (1987) Two forms of 1 B236/myelin-associated glycoprotein, a cell adhesion molecule for postnatal neural development, are produced by alternative splicing. Proc Natl Acad Sci USA 84: $4337-4342$.

Lassar AB, Buskin JN, Lockshon D, Davis RL, Apone S, Hauschka $\mathrm{SD}$, Weintraub H (1989) MyoD is a sequence-specific DNA binding protein requiring a region of myc homology to bind to the muscle creatin kinase enhancer. Cell 58:823-831.

Lees MB, Brostoff SW (1984) Proteins of myelin. In: Myelin (Morell P, ed), pp 197-224. New York: Plenum.

Lemke G (1988) Unwrapping the gene sof myelin. Neuron 1:535-543.

Lemke G, Lamar E, Patterson J (1988) Isolation and analysis of the gene encoding peripheral myelin protein zero. Neuron 1:73-83.

Levine M, Hoey T (1988) Homeobox proteins as sequence-specific transcription factors. Cell 55:537-540.

Luckow B, Schütz G (1988) CAT constructions with multiple unique restriction sites for the functional analysis of eukaryotic promotors and regulatory elements. Nucleic Acids Res 15:5490.

Macklin WB, Weill CL, Deininger PL (1986) Expression of myelin proteolipid and basic protein mRNAs in cultured cells. J Neurosci Res 16:203-217.

Macklin WB, Campagnoni CW, Deininger PL, Gardinier MV (1987) Structure and expression of the mouse myelin proteolipid protein gene. J Neurosci Res 18:383-394.

Mangalam HJ, Albert VR, Ingraham HA, Kapiloff M, Wilson L, Nelson C, Elsholtz H, Rosenfeld MG (1989) A pituitary POU domain protein, Pit-1, activates both growth hormone and prolactin promotors transcriptionally. Genes Dev 3:946-958.

McMorris FA (1977) Norepinephrine induces glial-specific enzyme activity in cultured glioma cells. Proc Natl Acad Sci USA 74:45014505 .

Milner RJ, Lai C, Nave KA, Lenoir D, Ogata J, Sutcliffe JG (1985) Nucleotide sequences of two mRNAs for rat brain myelin proteolipid protein. Cell 42:931-939.

Miura M, Tamura T, Aoyama A, Mikoshiba M (1989) The promotor elements of the mouse myelin basic protein gene function efficiently in NG108-15 neuronal/glial cells. Gene 75:31-38.

Mori N, Steim R, Sigmund O, Andersen D (1990) A cell type-preferred silencer element that controls the neural-specific expression of the SCG10 gene. Neuron 4:583-594.

Nave KA, Milner RJ (1989) Proteolipid proteins: structure and genetic expression in normal and myelin-deficient mutant mice. CRC Crit Rev Neurobiol 5:65-91.

Nave KA, Lai C, Bloom FE, Milner RJ (1986) Jimpy mutant mouse: a 74 base deletion in the mRNA for myelin proteolipid protein (PLP) and evidence for a primary defect in RNA splicing. Proc Natl Acad Sci USA 83:9264-9268.

Nave KA, Lai C, Bloom FE, Milner RJ (1987) Splice site selection in the gene for myelin proteolipid protein (PLP) and primary structure of the DM-20 protein of CNS myelin. Proc Natl Acad Sci USA 84: 5665-5669.

Nave KA, Weinmaster G, Lai C, Lemke G (1988) Proteolipid protein (PLP) gene expression and promotor activity in C6 glioblastoma and cultured Schwann cells. Soc Neurosci Abstr 14:625.

Nelson C, Albert VR, Elsholtz HP, Lu LIW, Rosenfeld MG (1988) Activation of cell-specific expression of rat growth hormone and prolactin genes by a common transcription factor. Science 239:14001405 .

Nelson C, Shen LP, Meister A, Fodor E, Rutter WJ (1990) Pan: a transcriptional regulator that binds chymotrypsin, insulin, and AP-4 enhancer motifs. Genes Dev 4:1004-1012.

Ohlsson H, Edlund T (1986) Sequence-specific interactions of nuclear factors with the insulin gene enhancer. Cell 45:35-44. 
Raff MC (1989) Glial cell diversification in the rat optic nerve. Science 243:1450-1455.

Raff MC, Miller R, Noble M (1983) A glial progenitor cell that develops in vitro into an astrocyte or an oligodendrocyte depending on the culture medium. Nature 303:390-396.

Raju TR, Bignami A, Dahl D (1980) Glial fibrillary acidic protein in monolayer cultures of C -6 glioma cells: effect of aging and dibutyryl cyclic AMP. Brain Res 200:225-230.

Richardson WD, Pringle N, Mosley M, Westermark B, Dubois-Dalcq $M$ (1988) A role for platelet-derived growth factor in normal gliogenesis in the central nervous system. Cell 53:309-319.

Roach A, Boylan K, Horvath S, Prusiner SB, Hood L (1983) Characterization of cloned cDNA representing rat myelin basic protein: absence of expression in brain of shiverer mutant mice. Cell 34:799806.

Schachner M, Kim SK, Zehnle R (1981) Developmental expression in central and peripheral nervous system of oligodendrocyte cell surface antigens (O-antigens) recognized by monoclonal antibodies. Dev Biol 83:328-338.

Schnitzer J, Franke WW, Schachner M (1981) Immunocytochemical demonstration of vimentin in astrocytes and ependymal cells of developing and adult mouse nervous system. J Cell Biol 90:435-447.

Sehgal A, Patil N, Chao M (1988) A constitutive promoter directs expression of the nerve growth factor receptor gene. Mol Cell Biol 8: 3160-3167.

Takahashi N, Roach A, Teplow DB, Prusiner SB, Hood L (1985) Cloning and characterization of the myelin basic protein gene from mouse: one gene can encode both $14 \mathrm{kd}$ and $18.5 \mathrm{kd}$ MBPs by alternate use of exons. Cell 42:139-148.

Volpe JJ, Fulimoto K, Marasa JC, Agrawal HC (1975) Relation of C6 glial cells in culture to myelin. Biochem J 152:701-703.

Wigler M, Sweet R, Sim GK, Wold B, Pellicer A, Lacy E, Maniatis T, Silverstein S, Axel R (1979) Transformation of mammalian cells with genes from procaryotes and eucaryotes. Cell 16:777-785.

Wingender $E$ (1988) Compilation of transcription regulating proteins Nucleic Acids Res 16:1879-1902.

Winoto A, Baltimore D (1989) Alpha beta lineage specific expression of the alpha $T$ cell receptor gene by nearby silencers. Cell 59:649665 . 